\title{
The indicator of a happy, long and sustainable life
}

\author{
Renaud Gaucher $^{1}$ (D) Issaka Dialga ${ }^{2,3} \cdot$ Coralie Vennin $^{4}$
}

Accepted: 31 May 2021 / Published online: 22 June 2021

(c) The Author(s) 2021, corrected publication 2021

\begin{abstract}
Many indicators are used to measure the quality of life of people and, consequently, these can be used to inform us about the quality of public policies. We propose to clarify this situation by asking one simple question: What is really important for us as an individual? This question can be asked to anyone and we could build a main indicator for public policies using this question and the responses of people. Our personal response is the following: What is really important for us as an individual is to live a happy and long life, and a life that does not prevent following generations from having lives as happy and long as ours, that is a sustainable life. We have built an indicator that fits this purpose. As we are negative utilitarianists and we consider that reducing premature deaths is more important than lengthening the duration of life, the indicator follows these two approaches. We give the cross-sectional results of the indicator of a happy, long and sustainable life, and we discuss the advantages and shortcomings of the indicator and avenues for future research.
\end{abstract}

Keywords Indicator · Public policy $\cdot$ Sustainability $\cdot$ Happiness $\cdot$ Life expectancy $\cdot$ Quality of life

\section{Introduction}

A lot of single indicators are used to measure the quality of life of people and, consequently, used to inform us about the quality of public policies. Diener \& Suh (1997) explain that there are three kinds of indicators: economic, social and subjective indicators. Economic indicators include Gross Domestic Product (GDP), GDP per capita and unemployment rate. Social indicators include, for example, indicators such as infant mortality, levels of crime and greenhouse gas emissions. Diener \& Suh (1997) state that indicators derived from domains such as ecology, human rights, welfare, and education are frequently

Renaud Gaucher

renaudgaucher@gmail.com

1 Erasmus Happiness Economics Research Organization, Erasmus University Rotterdam, Rotterdam, Netherlands

2 Department of Economics, University of Nantes, Nantes, France

3 Department of Economics, University Thomas Sankara, Ouagadougou, Burkina Faso

4 Bordeaux, France 
sampled as social indicators, while subjective indicators include such indicators as life satisfaction and domain satisfactions.

Although GDP per capita is often brought to the fore as the main indicator to use to measure quality of life, this indicator has limits, which are mainly due to the limits of GDP as a measure (see Stiglitz Sen \& Fitoussi 2009; Boarini \& d'Ercole, 2013 for the limits of GDP) and it is better to mix single indicators and obtain composite indicators to measure better people's quality of life.

The Human Development Index (HDI) is one of the most well-known composite indicators. It is a summary measure of average achievement in what is perceived as key dimensions of human development for the designers and the users of this indicator: having a long life, being knowledgeable and having a decent standard of living. The health dimension is measured using life expectancy at birth, the education dimension is assessed using years of schooling for adults aged 25 years and more and expected years of schooling for children starting school. The standard of living dimension was evaluated using GDP per capita before 2010, and since then using Gross National Income (GNI). The scores of the threedimension indicators are aggregated into a composite indicator using geometric mean. ${ }^{1}$

There are a lot of single and composite indicators that can be used to measure the quality of life, and it is easy to design new composite indicators using new combinations of several single indicators and to consider that these combinations are better than the previous ones.

Imagine we have ten single indicators, this is a small number if we consider all the aspects of quality of life and all the single indicators we could find. How many composite indicators can we design using these ten single indicators?

The mathematical formula to answer this question is:

$$
\sum_{k=2}^{k=n} \frac{n !}{k !(n-k) !}
$$

where $n$ is the maximal number of single indicator and $k$ the number of single indicators that is selected. In our example, $n=10$ and $k$ ranges from 2 to $10 .^{2}$

With just ten single indicators, it is possible to design 1,013 different composite indicators.

How do we find a way to define what is the best indicator to use to measure quality of life and inform public policy-makers, or to define what are the best indicators?

Veenhoven (1996) gives a list of problems that certain single and composite indicators may have. Among these problems are arbitrary selection, arbitrary weights, mix of means and ends, mix of what is good for people and what is good for society. Taking into account these issues is a way to select better indicators.

In our opinion, the best indicator, or the best indicators, is a response to one simple question: What is really important for me as an individual?

There are two approaches to respond to this question: the deductive approach and the inductive approach. In the deductive approach, researchers and experts respond the question and develop an indicator that fits their answer. In the inductive approach, people respond to the question and researchers, or the people, develop an indicator using the responses of the people.

\footnotetext{
1 http://hdr.undp.org/en/content/human-development-index-hdi (the 3rd of March 2019).

2 As a composite indicator is made of no less than 2 single indicators, $\mathrm{k}$ cannot be equal to 1 .
} 
In this paper, we propose our personal answer to the question of what is really important for us as an individual. We consider that the really important things are ends, not means, the really important things are what we want, not how we get them. Our answer is that what is really important for us as an individual is to have a happy and long life, and a life that does not prevent following generations from having lives as happy and long as ours, that is a sustainable life. The indicator that fits our answer, and the one we will propose, is an indicator of a happy, long and sustainable life. Everybody could ask himself or herself the same question and design his or her own indicator for public policy. You can ask yourself the question and build your own indicator. A state can ask its citizens the same question, build a composite indicator using the items that are the most mentioned, and build public policies using this indicator.

Our answer is close to Veenhoven's Happy Life Years indicator (HLY) $(1996 ; 2004)$ and Veenhoven's work has had a strong influence on our thinking. The HLY indicator is used to measure the degree to which people live long and happily. To obtain a HLY score, life expectancy at birth in years is multiplied by average subjective appreciation of life on a $0-1$ scale. The Happy-Life-years indicator can be interpreted as the number of years the average citizen in a country lives happily at a certain time.

We added a further dimension to the Veenhoven's HLY indicator, sustainability, and we proposed a different approach to Veenhoven's approach, negative utilitarianism rather than utilitarianism and Potential Years of Life Lost (PYLL) rather than life expectancy at birth.

Our answer is close to the New Economics Foundation's Happy Planet Index. The Happy Planet Index combines four elements: well-being, ${ }^{3}$ life expectancy, inequality of outcomes and ecological footprint. We propose a different approach because we consider that all inequalities are not equal, some are more important than others. This is why the less happy, the unhappier an individual was, the more weight was given to him or her, and why the more premature a death was, the more weight was given to it. We also linked the ecological footprint of a specific country to its biocapacity. The ecological footprint of a country can be weak in absolute terms while it is important when taking into account the biocapacity of the country.

There are two ways to develop the indicator of a happy, long and sustainable life. The first way is to have three single indicators, one used to measure happiness, one used to measure the duration of life, and one used to measure sustainability. We will present what these single indicators can be in the Sects. 2, 3 and 4. The second way is to develop a composite indicator including the three single indicators mentioned above. We consider both ways relevant and using both ways simultaneously is the best way to use the indicator to implement and assess public policies. The interest of using a composite indicator is to summarize a situation with one number. Mixing happiness, duration of life and sustainability in one composite indicator could be considered putting together apples, oranges and bananas, and it is, however, as apples, oranges and bananas fall into a larger category, fruit, happiness, duration of life and sustainability fall also into a larger category, ultimate goals. This is also not the first time that researchers put together apples, oranges and bananas, see for example the HDI, and techniques exist to deal with units of measurement in composite indicators construction. We will present the indicator of a happy, long and sustainable life as a composite indicator in Sect. 5. As the indicator of a happy, long and sustainable life, as a composite indicator, is our personal answer to the question of what is really important

\footnotetext{
3 The New Economics Foundation defines well-being as life satisfaction, which is how we define happiness. Thus, happiness and well-being have the same meaning here.
} 
for us as an individual, the chosen weights, which reflect our opinion, are obviously subjective, and we choose equal weighting. We do not want to give a greater weight to one of the dimensions of the indicator. Of course, it is possible to decide to use another weighting, either democratically or out of necessity, for example for ecological purposes, or by using a statistical method. Becker et al, (2017) demonstrate that the weight assigned to a dimension cannot be directly interpreted as a measure of its importance to the value of the composite indicator. We discuss the advantages and the limitations of our proposal and suggest some avenues for future research in the Sect. 6.

\section{Happiness}

\subsection{Definition of happiness}

Veenhoven (1984) defines happiness as the subjective degree to which an individual judges the overall quality of his/her own life-as-a-whole favourably. In other words, how much one likes the life one leads. Happiness is an enduring satisfaction, unlike emotions that are short-lived. It is possible to be happy while experiencing negative emotions from time to time and conversely it is possible to be unhappy while experiencing positive emotions from time to time. Happiness is satisfaction with life as-a-whole, unlike satisfaction with one's work life, marriage, etc. which are satisfactions with life-aspects.

In Veenhoven's view (1984), when evaluating the favourableness of our life, we tend to use two more or less distinct sources of information: our affects and our thoughts. As a consequence, he sees happiness as having two components: the hedonic level of affect, the degree to which various affects that someone experiences are pleasant in character, and contentment, the degree to which an individual perceives his or her aspirations are met. These two components are important because they can be used to improve happiness. If we want to improve happiness, we have to increase positive emotions and, or decrease negative emotions. We can also bring the life we have and the life we want closer by decreasing our expectations and, or improving our life.

Philosophers and social scientists have proposed numerous definitions of happiness. Veenhoven's (1984) definition has at least five advantages. One, liking the life one leads is what most people want. Two, Veenhoven's definition of happiness can be summarized in a few simple words, which make it easy to use to empower human beings in their lives. Three, Veenhoven uses a word that lay people use, happiness, this is a way to help social scientists empower lay people. Most researchers in social sciences prefer to use expressions such as 'subjective well-being' and 'psychological well-being', but lay people do not use these expressions, and this makes it difficult for lay people to use these expressions to empower themselves. Four, Veenhoven's definition falls within utilitarian moral philosophy. As such it is a democratic alternative to paternalistic, ideological notions of what a good life should be. Five, how much one likes the life one leads can be easily measured using a scale.

Kahneman (1999) proposes a definition of happiness that captures happiness as it should be if our brains do not have biases. He calls his model 'objective happiness'. In this model, happiness is described as the average of instant utility over a period of time. Utility can be defined as a flow of positive and negative emotions and instant utility as the utility experienced at a time $\mathrm{t}$. 
Kahneman's model of objective happiness (1999) takes into account the fact that the human brain is biased by three phenomena: the overweight given to emotional events, the overweight given to recent events and duration neglect. This is the reason why Kahneman et al. (1997) make a distinction between experienced utility and remembered utility. For simplicity, we can use the word happiness rather than the word utility and say that experienced happiness may be significatively different from remembered happiness. The distinction between experienced happiness and remembered happiness is very powerful and it would be a good idea to use the concept of experienced happiness when thinking about public policies, however, it is difficult to measure experienced happiness over a long period of time.

\subsection{Measure of happiness}

The first and most important feature of a good measure of happiness is that this measure fits with the theoretical framework it falls within.

Here are some survey questions that fits Veenhoven's definition of happiness.

- 'On the whole how satisfied are you with the life you lead?' (used in Eurobarometer surveys since 1973)

- 'How do you feel about your life as a whole?' (Andrews \& Withey, 1976)

The best items fit the definition they are used to measure perfectly. As happiness is defined by Veenhoven, (1984) as liking the life one leads, the best item can be 'How much do you like the life you lead?'. This item is more beautiful in French, because the verb to use is 'aimer', which means 'to love'. A good translation of 'How much do you like the life you lead?' is 'A quel point aimez-vous la vie que vous menez?'.

If we ask ourselves how much we like the life we lead, we will use a verbal response to answer this question, for example 'very' or 'not at all', however, when surveying, it is better to use a numerical response scale to obtain better comparable data.

When a verbal response scale is used for an analysis, the collected results can be translated into numbers, however, the distance between words used in a verbal response scale may not be the same as the distance between the respective numbers, for example if we use a verbal response scale such as not at all $=1$, a little $=2$, moderately $=3$, quite a bit $=4$, very $=5$, the distance between 'not at all' and 'a little' may not be the same as the distance between 'a little' and 'moderately' while the distance between 1 and 2, and the distance between 2 and 3 are the same.

A systematic overview of all the variations in survey items on happiness can be found in the collection 'Measures of Happiness' of the World Database of Happiness (WDH).

Psychologists usually prefer to use scales with more than one item because they consider that the psychometric properties of multi-item scales are better (Churchill, 1979; Nunnally $\&$ Bernstein, 1994). Psychometric properties are sensitivity, reliability, and validity. AbdelKhalek, (2006) demonstrates that measuring happiness using the single-item scale 'Do you feel happy in general?' can have good temporal stability and concurrent, convergent, and divergent validity. Other studies show that single-item measures on different topics can have good psychometric properties (e.g. Wanous et al, 1997; Bergkvist \& Rossiter, 2007). 


\subsection{The negative utilitarianist approach and a negative utilitarianist measure of happiness}

Results on happiness can be used within an indicator and for themselves. When used for themselves, there are three ways to use them in public policies. One, the greatest happiness of the greatest number, this is the utilitarianist approach (Bentham, 1776/2001). Two, improving the degree of happiness of the happiest. Although there is no name for such an approach to our knowledge, we can consider that public policies that aim at giving more wealth to the wealthiest may pursue the underlying goal of improving the happiness of the happiest. Three, improving the degree of happiness of the less happy, the unhappiest, this is the negative utilitarianist approach (Popper, 1952).

We consider that the negative utilitarianist approach is the best approach. We can give two reasons to support this choice. One, at a personal level, we prefer to avoid bad conditions in our lives rather than to improve good conditions. Two, as Popper (1952) writes: 'human suffering makes a direct moral appeal for help, while there is no similar call to increase the happiness of a man who is doing well anyway.'

Practically, the negative utilitarianist approach has an issue: it is difficult to define precisely who the less happy/the saddest people are, because a threshold must be defined. This threshold may be a percentage of a whole population, a degree of declared happiness, or a deviation from an average or the median.

To get a measure of happiness that falls within the negative utilitarianist approach, it is possible to apply a negative utilitarianist treatment to the data, that is by weighting each degree of happiness differently so that the lower the degree of happiness, the highest the weight.

Our negative utilitarianist measure of happiness using a 1 to 10 scale is:

$$
\frac{\sum_{i=1}^{i=10} n_{i}\left(\frac{i}{10}\right)^{2}}{\sum_{i=1}^{i=10} n_{i}}
$$

where $\mathrm{i}$ and $\mathrm{n}$ denote respectively the degree of happiness, numerical response, assigned by the respondent and $\mathrm{n}$ number of respondents.

Happiness should be assessed on a 1 to 10 scale, then the mathematical expression above should be used, however, it is possible to convert any scale to a 1 to 10 scale (de Jonge 2015; de Jonge et al. 2014). When possible, it is preferable to use a 1 to 10 scale rather than a 0 to 10 scale, because a 0 to 10 scale may be problematic when weighting the degree 0 accordingly to the other degrees, however, this is a small issue because it does not change the results a lot.

As we value a negative utilitarianist approach to an utilitarianist approach, we consider that it is best to begin with a negative utilitarianist approach and we propose the following process. First, identify the less happy people, understand how public policies can create a more favourable environment for them and implement such policies; then, determine how public policies can create a favourable environment for the greatest happiness for the greatest number, and implement such policies; finally, determine if specific public policies can explain the degree of happiness of the happiest people, and, if they do, understand how they do and implement such policies. 


\section{Long life}

\subsection{Long life and happiness}

Veenhoven $(1996,2004)$ has developed an indicator that links happiness and duration of life through life expectancy at birth. Veenhoven, (2004) gives two reasons to explain why it is relevant to add life duration to happiness. One, it allows us to take into account the duration of happiness. If we are satisfied with the life we lead, it is reasonable to think that we want this life to continue. Two, longevity is an indicator of successful adaptation for all creatures. Any organism perishes if it fails to meet the demands of its environment. Veenhoven $(1996,2004)$ uses life expectancy at birth to operationalize life duration. As it is not possible to know the lifetime of a person before he or she dies, Veenhoven, (1996, 2004) needed a proxy measure of lifetime and life expectancy at birth provides him with this proxy measure.

It is possible to add the dimension of the duration of lifetime to Kahneman's (1999) model of objective happiness. Imagine two people who have the same, stable degree of instant utility over all their lives. This hypothesis is unrealistic, but it allows us to understand the importance of adding the duration of life to Kahneman's model of objective happiness. Imagine now that the only difference between these two people is that the first lives for 40 years and the second lives for 80 years. If we think of objective happiness as an integral rather than a means, then the second person has lived twice as much happiness as the first one and length of the lifetime matters.

\subsection{Reducing premature deaths is more important than lengthening the duration of life}

In a negative utilitarianist approach, the goal is to help reduce human suffering. If we adapt this approach to the issue of lifetime, then the main goal is to help reduce premature death. The more premature the deaths are, the more important the deaths are and the more important it is that public policies should be implemented aimed at preventing these deaths. Lengthening the duration of life comes second.

\subsection{An important limitation to the lengthening of lifetime}

Some researchers and firms are working on ways to lengthen significantly the duration of human life. The future being uncertain, we cannot know to what extent they will succeed, but we can look back in history and see that three hundred years ago, for example, in France, two children were needed to make one adult according to Goubert (1968). This means that only one in two children lived long enough to reproduce. In three hundred years, living conditions have changed. Today, in rich countries, people live on average more than seventy years.

If scientists do manage to lengthen the duration of the human life, some new issues will occur. As natural resources are limited, we will need to find ways to reduce the human population and find ways to use the limited resources of the Earth efficiently, and it is possible that a lengthen human lifespan will not be sustainable. 


\subsection{The choice of Potential Years of Life Lost (PYLL)}

It is not possible to measure the duration of life of a person when he or she is alive, because duration can only be calculated after death. Thus, we need a proxy variable to assess the duration of life.

Life expectancy at birth is calculated using the average age at death in a population age and, based on this calculation, an assumption of life expectancy is made for the living, however, the living conditions of the people can be very different from the conditions those now dead lived under. For example, economic collapses or wars can lead to an unforeseen decrease in the duration of lives, while scientific breakthroughs can generate unexpected increases.

Healthy life expectancy (Robine \& Ritchie, 1991; Sanders, 1964) might have been another option to use as proxy variable in the life duration calculation.

Life expectancy at birth and healthy life expectancy do not fall within our approach to which the more premature a death is, the more important this death is and the more important it is that public policies should be implemented aiming at avoiding this death. This is why we choose to use Potential Years of Life Lost (PYLL) as a proxy variable of duration of life. PYLL is a negative utilitarianist measure of duration of life. The calculation of PYLL involves summing up deaths occurring at each age and multiplying this with the number of remaining years to live up to a selected age limit, age 70 in OECD Health Statistics. ${ }^{4}$

Note: Potential Years of Life Lost works in the opposite way to the negative utilitarianist measure of happiness we saw in Sect. 2.3 and the measure of sustainability we will see in Sect. 4. The lower the number of Potential Years of Life Lost, the better.

\section{Sustainability}

\subsection{Sustainability, long life and happiness}

It is possible that people can live happy and long lives and leave a country with environmental conditions that are so bad that they put in danger the happiness and duration of lives of their descendants. Diamond (2005) shows that a civilization can collapse due to the environmental issues a civilization has generated.

If we take into consideration only happiness and sustainability, we can propose the following matrix, see Table 1 .

The best condition is an altruistic, happy society because in a such society people are generally happy and the way they live does not endanger the way their descendants will live.

Selfish, unhappy society is the worst condition. The people are generally unhappy and the way they live will endanger the way their descendants will live.

Between the best and the worst conditions, there are two intermediate and opposite conditions: a society in which people are generally happy, but their happiness is built on future bad living conditions for their descendants, and a society in which people are generally unhappy, but do not endanger the quality of their descendants' living conditions. In the

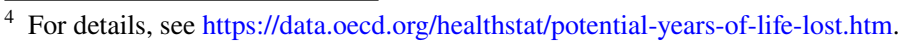


Table 1 The matrix of the altruistic-happy society

\begin{tabular}{|l|l|l|}
\hline & Unsustainable society* & Sustainable society* \\
\hline Unhappiness & Selfish unhappy society* & Altruistic unhappy society* \\
\hline Happiness & Selfish happy society* & Altruistic happy society* \\
\hline
\end{tabular}

* Note: We have written 'happy society' and 'unhappy society'. Our goal was to be understandable with a few words, however, as Veenhoven (1984) has explained, the term happiness should be used to describe the state of an individual person only, it does not apply to societies. Thus, a society cannot be said to be happy, at best, most of its members will consider themselves to be happy. Conversely, a society cannot be said to be unhappy, at worst, most of its members will consider themselves to be unhappy.

second condition, society demonstrates a high degree of generativity ${ }^{5}$ and a low degree of generativity in the first condition.

\subsection{Definition of sustainability}

Brown et al, (1987) give a review of how the word 'sustainability' is used by researchers and conclude that, if one accepts an anthropocentric view of sustainability, then there are three ways to define sustainability. In the narrowest sense, sustainability means the indefinite survival of the human species across all regions of the world. In a broader sense, sustainability means that human beings benefit from a quality of life beyond mere biological survival. In the broadest sense, sustainability includes the persistence of all components of the biosphere, even those with no apparent benefit to humanity.

The independent think tank Global Footprint Network uses the concept of ecological deficit/ reserve. A national ecological deficit occurs when the ecological footprint of a population exceeds the biocapacity of the land available to the population. A national ecological deficit means that the nation is importing biocapacity through trade, liquidating national ecological assets or emitting carbon dioxide waste into the atmosphere. A national ecological reserve exists when the biocapacity of a country exceeds its population's ecological footprint.

The concept of ecological deficit/reserve fits the narrowest sense of definition of sustainability of Brown et al, (1987), survival of human beings. If there is an ecological reserve, then human beings have natural resources to survive. The concept of ecological deficit/ reserve partially fits the definition of sustainability as life above biological survival. If there are not too many human beings, it is possible to have an ecological reserve and a certain degree of quality of life, however, if there are too many human beings and, or if the degree of quality of life is too high, then there is an ecological deficit. The concept of ecological deficit/reserve partially fits the definition of sustainability as persistence of all components of the biosphere, even those with no apparent benefit to humanity. Ecological reserve is good for allowing persistence of all components of the biosphere, however, even if there is an ecological reserve, it does not mean that every single component of the biosphere is free of danger generated by human beings.

${ }^{5}$ Generativity is a concept used in psychology to indicate that people care about their descendants. 
The concept of sustainability has been extended from the ecological sphere alone, leading to the concept of sustainable development. Alaimo and Maggino, (2020d) define sustainable development as 'processes and policies that allow an efficient use of the natural resources which are limited and non-renewable'. Policies that are said to fall within a sustainable development approach are implemented, however, some researchers explain that these policies may not reach their goals (e.g. Hickel \& Kallis, 2019).

\subsection{The sustainability ratio}

Global Footprint Network operationalizes the concept of ecological deficit/ reserve by subtracting the ecological footprint of a region or country from the biocapacity of the region or country.

In order to implement a measure of sustainability in our indicator, we choose to operationalize the concept of ecological deficit/ reserve differently and to divide the biocapacity of a country by the ecological footprint of the same country. We called this ratio the sustainability ratio. If the sustainability ratio is equal to or greater than 1 , then the biocapacity of the country is sufficient. If the ratio is less than 1 , then the biocapacity of the country is not sufficient and the smaller the ratio is, the more difficult the ecological situation is.

If the sustainability ratio is strictly greater than 1.1 , then we replace the result of the ratio by 1.1. The reason for this choice is that we consider that a reasonable goal for a country is to have a biocapacity that equals its ecological footprint, which means a ratio of 1 , and that it is cautious to add a $10 \%$ safety margin in case an error is made during the calculation of the components of the ratio and to have a conservative ecological reserve, which means a ratio of 1.1 .

This choice can be debatable because it means that we consider that nature has to exist only to serve humanity. The higher the sustainability ratio is, the more space is given to a nature free from human activities. A space without any human activity would have a 0 ecological footprint and an infinite sustainability ratio. The reality, however, is that most countries do not reach a sustainability ratio of 1.1 nowadays.

\section{First results of the indicator of a happy, long and sustainable life as a composite indicator}

The indicator of a happy, long and sustainable life can be presented as three single indicators, see Sects. 2, 3 and 4, and as a composite indicator. Here we explain how we constructed the indicator of a happy, long and sustainable life as a composite indicator, and we give the results we obtained. As Maggino, (2017) states, this process is a combination of objectivity and subjectivity.

\subsection{Data}

Happiness. We used the 2014 data on happiness from the Pew Research Center in which happiness is measured using the national values for answers to the Cantril ladder question asking respondents to value their lives today on a 0 to 10 scale, with the worst possible life 
Table 2 Summary statistics of the three dimensions of the indicator before normalization

\begin{tabular}{lrrcrcc}
\hline & Mean & Median & Standard deviation & Minimum & Maximum & Observations \\
\hline $\begin{array}{l}\text { Negative utilitarianist } \\
\text { measure of happiness }\end{array}$ & 0.46 & 0.45 & 0.08 & 0.35 & 0.62 & 15 \\
Potential years of life lost & $4,520.69$ & $3,012.70$ & $3,909.69$ & $2,275.60$ & $17,962.70$ & 15 \\
Sustainability ratio & 0.42 & 0.37 & 0.28 & 0.06 & 1.1 & 15 \\
\hline
\end{tabular}

as a 0 and the best possible life as a 10. The Pew Research Center provided free frequency distributions to calculate the negative utilitarianist measure of happiness. We then calculated the negative utilitarianist measure of happiness for each country in 2014, see Sect. 2.3 for the formula.

Note: the Cantril ladder has a weakness. It is a measure of contentment, the degree to which an individual perceives his or her aspirations are met, not a measure of happiness as liking the life one leads. Another weakness of the Cantril ladder is that it anchors in possible lives rather than in wanted lives.

Long life. We used the 2014 data on Potential Years of Life Lost from the OECD.

Sustainability. We collected the data of Global Footprint Network, an independent think tank, on biocapacity per country and ecological footprint per country for 2014 . We then calculated the sustainability ratio for each country in 2014 .

Data were not available for each country. We got the data we needed to calculate the results of the indicator of a happy, long and sustainable life for 15 countries. This lack of data was due to the fact that PYLL was not evaluated for a lot of countries, and to the fact we did not find a lot of free, valid data on happiness frequency distribution, see Table 2 the summary statistics of the three dimensions of the indicator of a happy, long and sustainable life before normalization.

\subsection{Measurement model, normalization and aggregation}

\subsubsection{Measurement model}

Two kinds of measurement model exist: the reflective model and the formative model. In the reflective model, causality comes from the latent variable to the single indicators, a change in the latent variable may cause variations in the single indicators. In the formative model, it is the opposite, causality comes from the single indicators to the latent variable, and single indicators can also have positive, negative or zero correlations (Mazziotta \& Pareto, 2019).

The choice between the two kinds of model depends on the nature of the phenomenon being measured and its definition (Maggino, 2017). The indicator of a happy, long and sustainable life as a composite indicator includes three single indicators, happiness, long life and sustainability, and any change in one or more of these indicators will cause a change in the composite indicator result. Correlations between single indicators can be positive, negative or null. The measurement model of the indicator of a happy, long and sustainable life is a formative model. 


\subsubsection{Normalization}

Normalization aims at unifying different measurement units when data for all variables do not have a common or equivalent measurement. OECD and $\mathrm{JRC}^{6}$, (2008) make a list of nine different methods to normalize data. Three methods could have been used to construct our composite indicator: standardization, min-max method and distance to a reference method. We chose to apply the min-max method. Standardization depends on the sample or population. Distance to a point does not take into account the minimal values.

For each single indicator for a given country, the mathematical formula of the min-max method is as follows:

$$
I_{i j}=\frac{V_{i j}-V_{\min }}{V_{\max }-V_{\min }}
$$

where $V_{i j}$ is the collected data for the dimension $i$, for the country $j, V_{\min }$ the minimum value and $V_{\max }$ the maximum value.

OECD and JRC, (2008) suggest to use minimum and maximum values across all countries in the min-max method, but indicators such as the HDI were constructed using theoretical and subjectively selected values as minimum and maximum values.

We chose to use theoretical and subjectively selected values for three reasons. One, the theoretical and subjectively selected value are not dependent on a sample or a population. As a consequence, the results of an indicator for which we use these kinds of value are not dependent on a sample or a population. Two, using minimal and maximal values across all countries in the min-max method may give a false image of the reality. For example, we saw that a country, Mexico, had a score of 6.2 on 0 to 10 scale and, after a normalization for which we used the minimal and maximal values across countries, a score of 10 on a 0 to 10 scale. The reason for this discrepancy is that Mexico is the country with the highest degree of happiness in our sample when happiness is measured using our negative utilitarianist formula. Three, what matters is the distance between a country and the optimal and the worst conditions, not the distance to the other countries.

We chose the following theoretical and subjectively selected values as minimal and maximal values, see Table 3 .

PYLL is not calculated for a lot of countries. In our sample the country with the worst situation regarding PYLL is South Africa with 17,962 potential years of life lost. It is likely that some other countries have a much higher number of potential years of life lost. According to the World Bank, life expectancy in South Africa was approximately 61 years

Table 3 The minimal and maximal theoretical and subjectively selected values of the sub-indicators the indicator of a happy, long and sustainable life

\begin{tabular}{lll}
\hline & Min & Max \\
\hline $\begin{array}{l}\text { Negative utilitarianist measure of hap- } \\
\text { piness }\end{array}$ & 0 & 10 \\
$\begin{array}{l}\text { Potential Years of Life Lost } \\
\text { Sustainability ratio }\end{array}$ & 0 & $50,000^{*}$ \\
\hline
\end{tabular}

*Subjectively selected value

${ }^{6}$ Joint Research Centre. 
in 2014, while it was 50.6 in the Central Africa Republic. We can then hypothesize that the number of potential years of life lost is much higher in the Central Africa Republic. We chose 50,000 as the maximal value for PYLL, however, this choice will have to be reassessed, once PYLL has been calculated for most of the countries in the world.

If the sustainability ratio is strictly greater than 1.1 , then we replace the result of the ratio by 1.1 . See Sect. 4.3 for the reason.

\subsubsection{Aggregation}

All weighting methods are not compatible with all aggregation methods (OECD and the JRC, 2008). As we chose to use equal weighting, linear aggregation, multi-criteria aggregation and geometric aggregation, could be applied (OECD and the JRC, 2008).

The linear aggregation method is based on an assumption of perfect substitutability between the different components of a composite indicator. When the dimensions of an indicator are complementary, requiring an equal effort, the method resulting from the multi criteria analysis is more appropriate (Munda 2005; OECD and JRC 2008; Dialga and Le 2017; Dialga, 2018). Geometric aggregation allows for some flexibility of compensation between index components at given thresholds. This method of aggregation is increasingly used in the construction of indicators, e.g. the HDI from 2010 (Herrero, Martínez and Villar, 2010) and the Sustainability Index of Mining Countries (Dialga, 2018).

In addition, the three components of the indicator of a happy, long and sustainable life interact with each other. Geometric aggregation is precisely the method that allows us to take interaction effects into account. Moreover, it is reasonable to assume that the three variables selected make a decreasing marginal contribution to the indicator we construct. In other words, small values of these variables make a greater contribution to the composite scores of the countries, but as these variables take on larger values, they contribute less and less to the overall score. This is something valuable in a negative utilitarianist approach.

The mathematical formula of geometric aggregation is as follows:

$$
\begin{gathered}
\forall I_{i}>0, \\
C I_{j}=\prod_{i=1}^{n}\left(I_{i}\right)^{w_{i}}
\end{gathered}
$$

where $C I_{j}$ denotes the composite score of the indicator for the country $j, I_{i}$ is the normalized sub-indicator, and $w_{i}$ is the weight associated with $I_{i}$. As all dimensions measured by the sub-indicators $I_{i}$ are assumed to have the same importance, $I_{i}$ are equally weighted; thus,

$$
w_{i}=\frac{1}{n}
$$

with $n$ the number of sub-indicators.

Mathematical constraint $\forall I_{i}>0$ must be fulfilled because, if one of the values is 0 in a geometric aggregation, then the result of the geometric aggregation is 0 . As the indicator falls within a negative utilitarianist approach, it would not be an issue if this theoretical possibility occurred. In practice, none of the three dimensions of the composite indicator can 
take the value 0 after normalization. No country has each person of its whole population declaring they are at the lowest degree of a scale used to measure happiness. Sadly, no country has a population for which each individual reaches the age of 70. A country is by definition a territory where human beings live and, as a consequence, have an ecological footprint.

Note: despite its success, the aggregative approach, that includes linear and geometric aggregative methods, has been criticized as inappropriate and often inconsistent from both conceptual and methodological perspectives (Freudenberg, 2003; Maggino, 2017). The non-aggregative approach, mainly multi-criteria analysis, is increasingly used by the experts because of assumptions of non-compensability between dimensions. The nonaggregative approach allows some limits of the aggregative one to be overcome, as recently highlighted successively in Alaimo et al, (2020a), Alaimo et al, (2020b) and Alaimo et al, (2020c). Since the indicator of a happy, long and sustainable life is based on a negative utilitarianist approach, the geometric aggregation method is more appropriate because this method values (overestimates) lower values more than higher values. Geometric aggregation respects the conceptual framework of the indicator.

\subsection{Controlling the relevance of our choices using the Mazziotta and Pareto flow chart}

In order to use the Mazziotta and Pareto flow chart (2013), we had to answer 4 questions:

- Are our single indicators substitutable or non-substitutable? The components of a composite indicator are called 'substitutable' if a deficit in one component may be compensated by a surplus in another.

- Is our aggregation simple or complex? An aggregation method is called 'simple' if its mathematical function is easily understandable.

- Are our comparisons absolute or relative? The comparisons are called 'absolute' if the definition of extreme values is independent from the data.

- Are our weights objective or subjective? The weights are called 'subjective' if they are set by people rather using a mathematical method.

As our single indicators were non-substitutable, our aggregation simple, our comparisons absolute and our weights subjective, the min-max method was chosen.

\subsection{The formula of the composite indicator of a happy, long and sustainable life}

After normalization, the formula to determine the indicator of a happy, long and sustainable life as a composite indicator is:

Indicator of a happy, long and sustainable life $=$ (Negative utilitarianist measure of happiness) x (1 - Potential Years of Life Lost per 100000 inhabitants) x (Biocapacity/Ecological footprint)

Some of the brackets are mathematically useless, but they allow us to show the three components of the indicator: a measure of happiness, life duration and sustainability.

See the negative utilitarianist measure of happiness we chose in Sect. 2.3. 
Potential Years of Life Lost works in the opposite way to the negative utilitarianist measure of happiness and the sustainability ratio. This is why the formula to take it into account for the PYLL is (1-PYLL).

If the sustainability ratio is strictly greater than 1.1 , then we replace the result of the ratio by 1.1. See Sect. 4.3 for the reason.

We finally put a cubic root over the results of the formula to take into account the fact that the formula is the multiplication of three components.

The developed form of the composite indicator is:

$$
\sqrt[3]{\frac{\frac{\sum_{i=1}^{i=10}\left(\frac{i_{j}}{10}\right)^{2}}{\sum n_{i j}}-V_{\min k}}{V_{\max k}-V_{\min k}} x\left(1-\frac{P Y L L_{j}-V_{\min k}}{V_{\max k}-V_{\min k}}\right) \times \frac{\frac{B I O_{j}}{E F_{j}}-V_{\min k}}{V_{\max k}-V_{\min k}}}
$$

where $\mathrm{i}$ the degree of happiness assigned by the respondent, $\mathrm{j}$ the country, $\mathrm{k}$ the dimension of the indicator, happiness, long life and sustainability, PYLL the value of the Potential Years of Life Lost, BIO the biocapacity of the country $\mathrm{j}$, and EF the ecological footprint of the country $\mathrm{j}$.

\subsection{Results and robustness}

\subsubsection{Why we prefer to use alphabetical order of countries over ranking}

When a characteristic is measured by country, countries are often ranked from the most successful country to the least. We prefer to use alphabetical order to present the indicator of a happy, long and sustainable life. This is a philosophical choice, and we can give at least five reasons to support this choice. One, we think that living a happy, long and sustainable life should be for a country, and humanity as a whole, the main goals of public policy, however, some people and countries could disagree, and they would be right to do so because they could have a different answer to the question of what is really important for ourself. Two, even if countries have the same goals, it is possible to disagree on how hard and high to strive to reach each goal. Three, even if countries have the same goals and want to reach the same level for each goal, they may not have the same initial conditions and the same means. It is biased to compare a result without taking into account initial conditions and the means. Four, when it comes to happiness, it is a better strategy to focus on our own happiness rather than to make social comparison to be happier. Five, research on between-countries variations bring useful information and is always welcome, however, when ranking goes out the academic world, the understanding of rankings tend to become an underlying competition, and we want to avoid such a competition.

\subsubsection{Results by country}

The data we used allow us to show the cross-sectional results for 15 countries, see Table 4. We did not have enough data to show how the indicator of a happy, long and sustainable life evolves for a specific country, although we consider that this is the best way to present data.

A country where the inhabitants are very happy and live long may have bad result because its ecological footprint is much higher than its biocapacity. This is the case of 
Table 4 The data on the components of the indicator of a happy, long and sustainable life in 15 countries in 2014 and the results for the indicator

\begin{tabular}{lllll}
\hline & $\begin{array}{l}\text { Negative utilitarianist } \\
\text { measure of happiness }\end{array}$ & $\begin{array}{l}\text { Potential years of } \\
\text { life lost }\end{array}$ & $\begin{array}{l}\text { Sustainability } \\
\text { ratio }\end{array}$ & $\begin{array}{l}\text { Indicator of a happy, } \\
\text { long and sustainable } \\
\text { life }\end{array}$ \\
\hline Chile & 0.48 & 0.91 & 0.78 & 0.7 \\
Colombia & 0.53 & 0.9 & 1 & 0.78 \\
France & 0.43 & 0.93 & 0.52 & 0.6 \\
Germany & 0.46 & 0.94 & 0.32 & 0.52 \\
Greece & 0.34 & 0.94 & 0.33 & 0.48 \\
Israel & 0.57 & 0.95 & 0.05 & 0.3 \\
Italy & 0.42 & 0.95 & 0.19 & 0.43 \\
Japan & 0.39 & 0.95 & 0.11 & 0.35 \\
Mexico & 0.62 & 0.87 & 0.42 & 0.61 \\
Poland & 0.38 & 0.9 & 0.42 & 0.53 \\
South Africa & 0.45 & 0.64 & 0.28 & 0.43 \\
South Korea & 0.41 & 0.94 & 0.1 & 0.34 \\
Spain & 0.44 & 0.95 & 0.31 & 0.51 \\
Turkey & 0.39 & 0.91 & 0.4 & 0.52 \\
United States & 0.52 & 0.9 & 0.38 & 0.57 \\
\hline & & & &
\end{tabular}

Israel. People living in Israel are among the happiest in a negative utilitarianist approach among 15 countries, and have one of the lowest Potential Years of Life Lost per 100,000 inhabitants among the same 15 countries, but its sustainability ratio is the worst one and very close to zero.

\subsubsection{Robustness}

Dialga and Le, (2017) use, at different steps, the most used statistical methods to construct a composite indicator, compare the results they obtained, and demonstrate that these different statistical methods lead to different results. In their illustrative case, scores and ranking results fluctuate, although their results are robust.

We compared the results we obtained using the min-max method with the results of the distance to reference method. The results of the two methods were exactly the same. We explain this by the choice of our minimal values: all are 0 . We did not compare with the standardization because this method is based on the features of the samples, not the choice of theoretical and subjective minimal and maximal values. We compared the results we obtained using geometric aggregation with the results of the linear aggregation, see Table 5. The correlation between results obtained using geometric aggregation and those obtained using linear aggregation is 0.93 . Results using linear aggregation were always higher, particularly for the countries with the worst results, which gives a less bad perception of the countries with the worst results. Geometric aggregation is a better tool in a negative utilitarianist perspective, because it does not mitigate the worst situations. 
Table 5 Comparison of two methods of aggregation, geometric and linear aggregations

\begin{tabular}{lll}
\hline & Geometric aggregation & $\begin{array}{l}\text { Linear } \\
\text { aggrega- } \\
\text { tion }\end{array}$ \\
\hline Chile & 0.7 & 0.73 \\
Colombia & 0.78 & 0.81 \\
France & 0.6 & 0.63 \\
Germany & 0.52 & 0.57 \\
Greece & 0.48 & 0.54 \\
Israel & 0.3 & 0.52 \\
Italy & 0.43 & 0.52 \\
Japan & 0.35 & 0.48 \\
Mexico & 0.61 & 0.64 \\
Poland & 0.53 & 0.57 \\
South Africa & 0.43 & 0.46 \\
South Korea & 0.34 & 0.48 \\
Spain & 0.51 & 0.57 \\
Turkey & 0.52 & 0.57 \\
United States & 0.57 & 0.6
\end{tabular}

\subsubsection{Results within country and results by individual}

We presented the results for the indicator of a happy, long and sustainable life at the country level, however, it is possible to evaluate the indicator of a happy, long and sustainable life at a within-country level and at the individual level. Happiness is measured at the individual level and it is always possible to calculate a negative utilitarianist measure of happiness for any level we would like to do so, including within-country levels. Potential Years of Life Lost is usually evaluated at the country level. The OECD also provides data per gender. It should be possible to provide PYLL at a within-country level and, for an individual, by taking into account his or her characteristics such as gender, education and work. Biocapacity and ecological footprint can be calculated at a within-country level. For the individual level, it may be possible to evaluate a proxy of the ecological footprint using income. The higher an individual income is, the higher the ecological footprint is likely to be. Spending would probably be a better proxy than income, but it is easier to determine income than spending. The biocapacity of an individual is the biocapacity of his or her country divided by the number of inhabitants of the country.

\section{Discussion}

\subsection{Advantages of our proposal}

We consider that our method, the underlying philosophy of our indicator and our indicator have at least four advantages.

One, there are a lot of indicators for public policies and it is easy to develop new ones. We have proposed a method that is a simple, but very relevant question to construct and 
select better indicators for public policies among all the indicators that exist and all the indicators researchers will design in the future: what is really important for me as an individual? This question means that what is important is ultimate goals, not means, that all ultimate goals are not equal, and that a society can choose the ultimate goals it will pursue. It could even mean that a society could choose to pursue the ultimate goals of each individual individually.

Two, we proposed an indicator that is our personal response to the question 'What is really important for you as an individual?' and our answer is just a proposal. We do not say that our indicator is better. We just say that we consider it fits with the question we asked: we chose ultimate goals, and these goals were a limited number of goals.

Three, we highlighted the interest of a negative utilitarianist philosophy in the choice of an indicator and we proposed a negative utilitarianist indicator, which is uncommon. Usually, when an indicator uses a measure of happiness, the measure does not give more weight to the answers of the less happy/ the unhappiest. Usually, when an indicator uses a measure of the duration of life, the chosen measure is life expectancy at birth, not a measure that gives more weight to premature deaths.

Four, we consider that it is possible to make the indicator evolve. Many indicators of a happy, long and sustainable life are possible depending on social preferences and scientific debates. For example, we chose equal weighting, but it is possible to change it. If the concern for environmental issues grows, then it is possible to overweight the sustainability rate. Each dimension of the indicator of a happy, long and sustainable life can also be measured differently, and this measurement could be relevant. We proposed a negative utilitarianist measure of happiness, but another formula depending on to what extent negative utilitarianist we are could be proposed to get a negative utilitarianist measure of happiness. Another selected age limit could be chosen for the PYLL or another way to weight premature deaths to give more weight to the most premature deaths. Sustainability could be measured differently. Greenhouse gas emissions reflect energy consumption, energy consumption reflects transformation, and the more we transform our environment, the more we get adverse effects (Jancovici, 2013). Hence, it is possible to assess the ecological impact differently from our proposal. For example, Hickel, (2020) has developed the Sustainable Development Index (SDI), a composite indicator that retains the base formula of the HDI, but divides by the Ecological Impact Index (EII), an index in which two indicators of ecological impact are taken into account, $\mathrm{CO} 2$ emissions and material footprint (MF), both calculated in per capita consumption-based terms and rendered vis-à-vis planetary boundaries. Researchers and other experts who do not like our sustainability ratio can replace it with the EII or any other sustainability indicator they consider better than the sustainability ratio.

\subsection{Limitations}

We would like to discuss two limitations of the indicator of a happy, long and sustainable life and the way it might be used.

One, the indicator does not totally reflect the quality of the public policies of a country. The indicator of a country may be influenced by the public policies of another country. A country can destabilize another country, which may influence the indicator negatively through a reduction of the degree of happiness of its inhabitants and the duration of their lives. Global warming is expected to reduce the biocapacity of most countries. As global warming depends on the public policies of every country, even if the wealthiest countries 
and the most populous have more influence, the public policies of a country run by climate sceptics may influence negatively the future results of a country run by people organizing the ecological transition well.

Two, a public policy that could have a positive impact on the indicator of a happy, long and sustainable in the near future may have a negative impact in the distant future, and vice versa. For example, a certain overexploitation of the nature may offer people a happy and long life in the near future, however, this overexploitation may reduce the quality of living conditions in the distant future and will then have a negative impact on happiness and duration of life. Conversely, sustainability policy may decrease the quality of living conditions in the near future and then may decrease the degree of happiness and longevity, while reducing the risk of having less good, worse living conditions in the distant future may reduce the risk of having a less happy and less long life in the distant future.

\subsection{Some avenues for future research}

A lot of questions have no answer for now and these questions could be avenues for further research. For example, to what extent our answer to the question of what is really important for us as an individual is supported by other people, whether they are researchers or lay people? Can we find a better definition of what is an indicator of a happy, long and sustainable life? A better measurement? To what extent does the indicator of a happy, long and sustainable life tap something different from other composite indicators such as GDP per capita, HDI or SDI? In other words, what are the correlations between the indicator of a happy, long and sustainable life and other indicators? Our indicator is focused on ends, not means. What are the best means to get the best results in the long term? Is it possible to find common determinants for the three dimensions of the indicator?

Open Access This article is licensed under a Creative Commons Attribution 4.0 International License, which permits use, sharing, adaptation, distribution and reproduction in any medium or format, as long as you give appropriate credit to the original author(s) and the source, provide a link to the Creative Commons licence, and indicate if changes were made. The images or other third party material in this article are included in the article's Creative Commons licence, unless indicated otherwise in a credit line to the material. If material is not included in the article's Creative Commons licence and your intended use is not permitted by statutory regulation or exceeds the permitted use, you will need to obtain permission directly from the copyright holder. To view a copy of this licence, visit http://creativecommons.org/licenses/by/4.0/.

\section{References}

Abdel-Khalek, A. M. (2006). Measuring happiness with a single-item scale. Social Behavior and Personality: An International Journal, 34(2), 139-150.

Alaimo, L. S., Arcagni, A., Fattore, M., \& Maggino, F. (2020a). Synthesis of multi-indicator system over time A poset-based approach. Social Indicators Research, 1, 23.

Alaimo, L. S., Arcagni, A., Fattore, M., Maggino, F., \& Quondamstefano, V. (2020b). Measuring equitable and sustainable well-being in Italian regions The non-aggregative approach. Social Indicators Research, 1, 23.

Alaimo, L. S., Ciacci, A., \& Ivaldi, E. (2020c). Measuring sustainable development by non-aggregative approach. Social Indicators Research, 1, 22.

Alaimo, L. S., \& Maggino, F. (2020). Sustainable development goals indicators at territorial level: Conceptual and methodological issues-the Italian perspective. Social Indicators Research, 147(2), 383-419. 
Andrews, F. W., \& Withey, S. B. (1976). Social indicators of well-being: Americans perceptions of life quality. Plenus.

Becker, W., Saisana, M., Paruolo, P., \& Vandecasteele, I. (2017). Weights and importance in composite indicators: Closing the gap. Ecological Indicators, 80, 12-22.

Bentham, J. (2001). A fragment on government. The Lawbook Exchange. (Originally published in 1776)

Bergkvist, L., \& Rossiter, J. R. (2007). The predictive validity of multiple-item versus single-item measures of the same constructs. Journal of Marketing Research, 44(2), 175-184.

Boarini, R., \& d'Ercole, M. M. (2013). Going beyond GDP: An OECD perspective. Fiscal Studies, 34(3), 289-314.

Brown, B. J., Hanson, M. E., Liverman, D. M., \& Merideth, R. W. (1987). Global sustainability: toward definition. Environmental Management, 11(6), 713-719.

Churchill, G. A., Jr. (1979). A paradigm for developing better measures of marketing constructs. Journal of Marketing Research, 16(1), 64-73.

De Jonge, T. (2015). Different survey questions on the same topic. Erasmus University Rotterdam. http:// hdl.handle.net/1765/78339

De Jonge, T., Veenhoven, R., \& Arends, L. (2014). Homogenizing responses to different survey questions on the same topic: proposal of a scale homogenization method using a reference distribution. Social Indicators Research, 117(1), 275-300.

Dialga, I. (2018). A sustainability index of mining countries. Journal of Cleaner Production, 179, $278-291$.

Dialga, I., \& Le, H. G. T. (2017). Highlighting methodological limitations in the steps of composite indicators construction. Social Indicators Research, 131(2), 441-465.

Diamond, J. (2005). Collapse: how societies choose to fail or succeed. Penguin.

Diener, E., \& Suh, E. (1997). Measuring quality of life: Economic, social, and subjective indicators. Social Indicators Research, 40(1-2), 189-216.

Freudenberg, M. (2003). Composite indicators of country performance: A critical assessment. OECD Publishing.

Goubert, P. (1968). Cent mille provinciaux au XVIIe siècle. Flammarion.

Herrero, C., Martínez, R., \& Villar, A. (2010). Improving the Measurement of Human Development. Human Development Research Paper.

Hickel, J. (2020). The sustainable development index: measuring the ecological efficiency of human development in the anthropocene. Ecological Economics, 167, 106331.

Hickel, J., \& Kallis, G. (2020). Is green growth possible ? New Political Economy, 25(4), 469-486.

Jancovici, J.-M. (2013). Transition énergétique pour tous : Ce que les politiques n'osent pas vous dire. Odile $\mathrm{Jacob}$.

OECD \& JRC (2008). Handbook on constructing composite indicator Methodology and user guide. OECD publishing.

Kahneman, D. (1999). Objective happiness. In D. Kahneman, E. Diener, \& N. Schwarz (Eds.), Well-being: the foundations of hedonic psychology (pp. 3-25). Russell Sage Foundation.

Kahneman, D., Wakker, P. P., \& Sarin, R. (1997). Back to bentham? explorations of experienced utility. The Quarterly Journal of Economics, 112(2), 375-406.

Maggino, F. (2017). Developing Indicators and Managing the Complexity. In F. Maggino (Ed.), Complexity in Society: from indicators construction to their synthesis (pp. 87-114). Springer.

Mazziotta, M., \& Pareto, A. (2013). Methods for constructing composite indices: One for all or all for one. Rivista Italiana Di Economia Demografia e Statistica, 67(2), 67-80.

Mazziotta, M., \& Pareto, A. (2019). Use and misuse of PCA for measuring well-being. Social Indicators Research, 142(2), 451-476.

Munda, G. (2005). "Measuring sustainability": a multi-criterion framework. Environment, Development and Sustainability, 7(1), 117-134.

Nunnally, J. C., \& Bernstein, I. H. (1994). Psychometric theory. McGraw-Hill.

Popper, K. R. (1952). The open society and Its enemies. Routledge \& Kegan Paul.

Robine, J. M., \& Ritchie, K. (1991). Healthy life expectancy: evaluation of global indicator of change in population health. British Medical Journal, 302(6774), 457-460.

Sanders, B. S. (1964). Measuring community health levels. American Journal of Public Health and the Nations Health, 54(7), 1063-1070.

Stiglitz J.E., Sen A.K., Fitoussi J.P. (2009). Rapport de la Commission sur la mesure des performances économiques et du progrès social.

Veenhoven, R. (1984). Conditions of happiness. Dordrecht/Boston: D.Reidel.

Veenhoven, R. (1996). Happy life expectancy. Social Indicators Research, 39(1), 1-58. 
Veenhoven, R. (2004). Happy life years: A measure of gross national happiness. In K. Ura \& K. Galay (Eds.), Gross national happiness and development, Proceedings of the first international seminar on Operationalization of Gross National Happiness. (pp. 287-318). Thimphu, Bhutan: Center of Bhutan Studies.

Wanous, J. P., Reichers, A. E., \& Hudy, M. J. (1997). Overall job satisfaction: how good are single-item measures? Journal of Applied Psychology, 82(2), 247.

Publisher's Note Springer Nature remains neutral with regard to jurisdictional claims in published maps and institutional affiliations. 